\title{
BMJ Open Scales for predicting risk following self-harm: an observational study in 32 hospitals in England
}

\author{
L Quinlivan, ${ }^{1}$ J Cooper, ${ }^{1}$ S Steeg, ${ }^{1}$ L Davies, ${ }^{2}$ K Hawton, ${ }^{3}$ D Gunnell, ${ }^{4}$ N Kapur ${ }^{1}$
}

To cite: Quinlivan L, Cooper J, Steeg S, et al. Scales for predicting risk following self-harm: an observational study in 32 hospitals in England. BMJ Open 2014;4:e004732. doi:10.1136/bmjopen-2013004732

- Prepublication history for this paper is available online. To view these files please visit the journal online (http://dx.doi.org/10.1136/ bmjopen-2013-004732)

Received 20 December 2013 Accepted 11 April 2014

\section{CrossMark}

${ }^{1}$ Centre for Mental Health and Risk, University of Manchester, Manchester, Lancashire, UK

${ }^{2}$ Institute of Population Health, University of Manchester, Manchester, Lancashire, UK

${ }^{3}$ Centre for Suicide Research, University Department of Psychiatry, Warneford Hospital, Oxford, UK

${ }^{4}$ School of Social and Community Medicine, University of Bristol, Bristol, UK

\footnotetext{
Correspondence to L Quinlivan; leah.quinlivan@manchester. ac.uk
}

\section{ABSTRACT}

Objective: To investigate the extent to which risk scales were used for the assessment of self-harm by emergency department clinicians and mental health staff, and to examine the association between the use of a risk scale and measures of service quality and repeat self-harm within 6 months.

Design: Observational study.

Setting: A stratified random sample of 32 hospitals in England.

Participants: 6442 individuals presenting with selfharm to 32 hospital services during a 3-month period between 2010 and 2011.

Outcomes: 21 -item measure of service quality, repeat self-harm within 6 months.

Results: A variety of different risk assessment tools were in use. Unvalidated locally developed proformas were the most commonly used instruments (reported in $\mathrm{n}=22(68.8 \%)$ mental health services). Risk assessment scales were used in one-third of services, with the SAD PERSONS being the single most commonly used scale. There were no differences in service quality score between hospitals which did and did not use scales as a component of risk assessment (median service quality score (IQR): $14.5(12.8,16.4)$ vs $14.5(11.4,16.0)$, $\mathrm{U}=121.0, \mathrm{p}=0.90$ ), but hospitals which used scales had a lower median rate of repeat self-harm within 6 months (median repeat rate (IQR): $18.5 \%$ vs $22.7 \%, \mathrm{p}=0.008$, IRR $(95 \% \mathrm{Cl}) 1.18$ (1.00 to 1.37). When adjusted for differences in casemix, this association was attenuated (IRR=1.13, $95 \% \mathrm{Cl}(0.98$ to 1.3$)$ ).

Conclusions: There is little consensus over the best instruments for risk assessment following self-harm. Further research to evaluate the impact of scales following an episode of self-harm is warranted using prospective designs. Until then, it is likely that the indiscriminant use of risk scales in clinical services will continue.

\section{BACKGROUND}

Hospital services play an important role in engaging people who self-harm and treat approximately 220000 episodes of self-harm in England annually. ${ }^{1}$ Self-harm is associated with a high risk of suicide and other adverse

\section{Strengths and limitations of this study}

- This study involved a large national sample of patients and services and it is likely that our findings will be generalisable to the rest of England and applicable to managed healthcare settings in other countries.

- We gathered responses from staff closely involved in self-harm service provision, and obtained copies of the risk tools.

- The study was observational in design and we cannot therefore infer causation.

- We only considered repeat episodes of self-harm presenting to the study hospitals, rather than community episodes or episodes presenting to other centres.

outcomes, ${ }^{2}{ }^{3}$ and good quality care has the potential to contribute significantly to suicide prevention. ${ }^{4}$ Psychosocial assessment is a key component of management. ${ }^{5}$ Clinical guidelines recommend a psychosocial assessment on presentation to the emergency department in order to gauge a person's mental state and willingness to remain for further assessment. ${ }^{6}$

Assessments by mental health staff typically take place at a later stage and involve a comprehensive evaluation of an individual's personal situation, history of self-harm, family history and mental state. ${ }^{78}$ The evaluation of risks (factors which may increase the likelihood of adverse outcomes) and patient needs (resulting, eg, from mental or physical illness or difficult social circumstances) are particularly important. ${ }^{9}$

Clinical assessments are social interactions between clinical staff and patients. ${ }^{10}{ }^{11}$ Some large quantitative studies have suggested that the process may itself have a protective effect against future suicidal behaviour. ${ }^{5} 12$ Assessments may be most helpful when used as an opportunity for clinicians to engage with patients and when patients have their need for help legitimised by the process. ${ }^{10}$ Tailored management plans can be developed, laying 
the foundation for longer term care. ${ }^{79}$ In contrast, other studies found that clinical assessments may sometimes encourage clinicians to disengage with patients and therefore negatively impact the therapeutic relationship. ${ }^{11}$

Risk assessment tools consisting of brief checklists of key risk factors, symptoms or antecedents are often regarded as core components of psychosocial assessments, but evidence for their effectiveness is limited. ${ }^{9} 1314$ Some guidelines advise against the use of these tools to determine clinical management. ${ }^{9}$ Others recommend that clinicians should only use scales that have undergone psychometric testing ${ }^{15}$ - for example, tested for their reliability, predictive ability and diagnostic accuracy, as well as construct, internal and external validity. ${ }^{16}$

A small number of descriptive studies have investigated the use of risk assessment tools in UK mental health services. ${ }^{13} 14 \quad 17$ Risk assessment tools vary widely in their type, structure and content, ${ }^{13} 1417$ with clinicians sometimes using locally developed and untested tools. ${ }^{15} 17$ The use of risk tools may also differ by care setting. For example, emergency department service pressures often necessitate rapid forms of assessment for physical risk, and scales are commonly used. ${ }^{18} 19$

There have been few studies on the use of risk scales across self-harm services. This is perhaps surprising given the high risk of suicide and other adverse outcomes in patients who self-harm. To our knowledge, no studies until now have investigated the association between the use of risk scales and service-level outcomes such as the quality of care or the rate of repetition of self-harm.

Using data from a study of 32 hospitals in England, ${ }^{20}$ we aimed to investigate the use of risk scales following self-harm in National Health Service (NHS) services. We included emergency departments and specialist mental health treatment settings in order to capture initial and subsequent risk assessments.

Specifically, the objectives of this study were:

1. To investigate the extent to which risk scales were used for the assessment of self-harm by emergency department clinicians and mental health staff.

2. To examine the association between use of a risk scale and service-level outcomes, such as service quality and repeat self-harm within 6 months.

\section{METHOD}

\section{Recruitment and study procedure}

For this observational study, we used data from a nationally representative stratified random sample of 32 hospitals in England. ${ }^{20}$ The methodological details are described elsewhere, ${ }^{20}$ but in brief, the sample was stratified to include small and large hospitals, and hospitals with low self-harm and high self-harm admission rates. The original sample was also stratified to ensure that four hospitals were selected within each of the eight former health regions.
Only hospitals with an emergency department were included in the sample.

Half of the hospitals were teaching hospitals (16/32). Fifteen of the hospitals served urban areas, 7 rural and 10 urban and rural equally. The number of beds ranged from 300 to 1865 . The hospital catchment population (based on hospital self-report) ranged from 120000 to 750000 . Specialist self-harm teams (ie, any liaison psychiatric service with at least one member of staff located within the emergency department) were in place in the majority of hospitals (29/32). Most of the assessments were carried out by a mental health nurse, including mental health liaison nurses and specialist self-harm teams (3109/4075), followed by a psychiatrist (799/ $4075)$ and 167 by another mental health professional (eg, social worker). The proportion of self-harm episodes given a psychosocial assessment by mental health staff varied from $24 \%$ to $88 \%$, with a median rate of $58 \% .^{20}$

Key emergency department and psychiatric staff (eg, consultants in emergency medicine and liaison psychiatry, mental health managers and mental health nurses) were interviewed at each site about self-harm service provision. As part of the interview, we asked about the methods used for assessing risk and for copies of the risk measures used. We were particularly keen to distinguish untested, locally developed instruments from published scales which had undergone some element of formal testing for their predictive ability. In the current study, we did not aim to compare the diagnostic accuracy of different instruments.

In each hospital, data were collected on consecutive presentations for self-harm over a 3-month period in 2010/2011. In total, over 6400 individuals were included. For the purposes of this study, self-harm was defined as 'a deliberate non-fatal act whether physical, drug dosage or poisoning, carried out in the knowledge that it was potentially harmful and in the case of drug overdose that the amount taken was excessive'. ${ }^{21}$

The data collection process for self-harm episodes at each site was classified as a local audit and therefore individual patient consent was not required.

\section{Outcomes}

\section{Self-harm service quality}

A service quality scale based on the Royal College of Psychiatrists' self-harm service standards was developed as part of previous work. ${ }^{20}{ }^{22}$ Questions on the scale pertained to key aspects of service provision; for example, supervision arrangements for all staff involved in psychosocial assessments, $24 \mathrm{~h}$ access to specialist mental health services and availability of rooms for privacy and confidentiality. There were 21 items in total (see table 1 for all items) each scored $0-1$ giving a potential scoring range from 0 to 21 . Responses from staff at interview were used to complete the scales and higher scores indicated a higher overall quality of self-harm services. 
Table 1 Service scale items with number and proportion of hospitals endorsing each item

\begin{tabular}{|c|c|c|c|}
\hline \multirow{2}{*}{$\begin{array}{l}\text { Item } \\
\text { number }\end{array}$} & \multirow[b]{2}{*}{ Service scale items } & \multicolumn{2}{|c|}{ Yes } \\
\hline & & $\mathbf{N}$ & Per cent \\
\hline 1 & $\begin{array}{l}\text { Is there a protocol/guideline/aide memoire for staff in the A\&E department for the immediate } \\
\text { medical management of self-harm? }\end{array}$ & 29 & 90.6 \\
\hline 2 & $\begin{array}{l}\text { Is there a protocol/guideline/aide memoire for staff in the A\&E department for the immediate } \\
\text { assessment of risk and severe mental disorder for patients who self-harm? }\end{array}$ & 28 & 87.5 \\
\hline 3 & Is there a designated self-harm specialist clinical service? (+A\&E liaison)* & 29 & 90.6 \\
\hline 4 & $\begin{array}{l}\text { Is there a local specific planning/working group (of the team who undertake the psychosocial } \\
\text { assessments) which meets at least once a year to plan/oversee the service for patients who } \\
\text { self-harm? }\end{array}$ & 22 & 68.8 \\
\hline 5 & $\begin{array}{l}\text { Are there psychosocial assessment training sessions for new staff who are involved in the } \\
\text { psychosocial assessment of patients? }\end{array}$ & 30 & 93.8 \\
\hline 6 & $\begin{array}{l}\text { Are there supervision arrangements in place for staff members (new and existing) who } \\
\text { undertake psychosocial assessments? }\end{array}$ & 23 & 71.9 \\
\hline 7 & $\begin{array}{l}\text { Are there written guidelines/a checklist, to assist psychiatric clinicians in the psychosocial } \\
\text { assessment of patients who self-harm? }\end{array}$ & 27 & 84.4 \\
\hline 8 & $\begin{array}{l}\text { Does the A\&E department have } 24 \mathrm{~h} \text { access to a psychiatrist, psychiatric nurse or social worker } \\
\text { who is able to undertake psychosocial assessments? }\end{array}$ & 30 & 93.8 \\
\hline 9 & If yes to 8, is immediate (within $15 \mathrm{~min}$ ) advice available over the telephone? & 22 & 68.8 \\
\hline 10 & If yes to 8 , is emergency attendance, when requested, available within $1 \mathrm{~h}$ ? & 7 & 40.6 \\
\hline 11 & $\begin{array}{l}\text { Do regular (at least once a year) service planning/strategy meetings take place between the } \\
\text { self-harm team/psychiatric service and the general medical service involved in the care of } \\
\text { patients who self-harm? }\end{array}$ & 31 & 96.9 \\
\hline 12 & $\begin{array}{l}\text { Are rooms which allow for privacy and confidentiality available for conducting interviews with } \\
\text { patients who self-harm either in or close to the A\&E department? }\end{array}$ & 21 & 65.6 \\
\hline 13 & $\begin{array}{l}\text { Does a formal arrangement exist with Social Services to visit and offer advice to patients who } \\
\text { self-harm who have significant social difficulties? }\end{array}$ & 31 & 96.9 \\
\hline 14 & $\begin{array}{l}\text { Can those admitted as inpatients remain in hospital until they have received a psychosocial } \\
\text { assessment? }\end{array}$ & 21 & 65.6 \\
\hline 15 & $\begin{array}{l}\text { Is there a policy stating that a patient's GP should be contacted within } 24 \mathrm{~h} \text { of patient discharge } \\
\text { from an A\&E department? }\end{array}$ & 26 & 81.3 \\
\hline 16 & $\begin{array}{l}\text { Is there a policy stating that a patient's GP should be contacted within } 24 \mathrm{~h} \text { of patient discharge } \\
\text { from a medical inpatient unit? }\end{array}$ & 13 & 40.6 \\
\hline 17 & $\begin{array}{l}\text { Are patients who self-harm routinely given printed material about local services, voluntary } \\
\text { groups and how to obtain access to them? }\end{array}$ & 6 & 18.8 \\
\hline 18 & Are there any formal links with non-statutory services (eg, self-help groups, the Samaritans)? & 15 & 46.9 \\
\hline 19 & $\begin{array}{l}\text { Has a system been set up for the monitoring of hospital attendance/discharge and referral of } \\
\text { patients who self-harm? }\end{array}$ & 13 & 40.6 \\
\hline 20 & Has there been any audit of the service for patients who self-harm in the past 2 years? & 13 & 40.6 \\
\hline
\end{tabular}

\section{Repetition of self-harm}

Individuals were followed up for 6 months after their index episode of self-harm. Repeat self-harm episodes leading to hospital presentation were identified through hospital databases. Presentations were linked to individuals through name, date of birth and NHS number.

\section{Analysis}

Our main analyses were descriptive. In order to investigate the association between use of risk scales and outcomes, we carried out additional analyses on aggregated hospital data. For this part of the analysis, we combined emergency department and mental health settings and compared hospitals using a tested tool $(n=14)$ to hospitals not using a tested tool $(n=18)$. This enabled us to capture the use of risk scales at any point along the care pathway. To test the robustness of the approach, we also carried out a sensitivity analysis based on emergency department assessments only. We initially used the Mann-Whitney $\mathrm{U}$ test to compare groups (services using and not using published risk scales) on overall service quality scores and repeat self-harm at 6 months.

Using negative binomial regression models, we then adjusted for risk factors previously shown to influence rate of repetition (history of self-harm, current psychiatric treatment, cutting as method, aged under 35 and gender). ${ }^{23} 24$ For risk factors which were continuous variables the sample was split into tertiles to facilitate clinical interpretation. One hospital was missing data on the outcome of repeat self-harm and was excluded from the analysis.

Statistical analysis was performed using SPSS V. $20^{25}$ and Stata release V.12. ${ }^{26}$ 


\section{RESULTS}

Risk and needs assessment by emergency

department staff

In 28 of $32(87.5 \%)$ hospitals there was a protocol or guideline for the immediate assessment of suicide risk for patients who presented with self-harm in the emergency department. Guidelines for the assessment of needs were available for patients who self-harm in 7 $(21.7 \%)$ of the 32 emergency departments. There was a referral policy regarding who should be referred for assessment to the psychiatric service in $15(46.9 \%)$ of the 32 emergency departments; $5(15.6 \%)$ also had a written guideline or checklist to assist in deciding who should be referred.

Twenty $(62.5 \%)$ of the hospitals reviewed had a specific triage procedure for patients who presented with selfharm. Triage is a formal dynamic process, performed at initial admission to the emergency department, whereby patients are prioritised on the basis of clinical urgency. ${ }^{27}$ Registered nurses typically assess physical needs, patient history and vital signs, evaluate if emergency interventions are necessary and assign a rating based on the urgency of the care required..$^{27}$ In 18/32 (56.6\%) hospitals there was a specific triage tool. The Manchester Triage tool $^{27}$ was used in $14(43.8 \%)$ of the hospitals, 3 $(9.4 \%)$ used an in-house locally developed triage tool and $1(3.1 \%)$ used the Mantis Triage tool.
Risk tools used by emergency department staff

Emergency department staff used a wide range of tools to assess risk following self-harm. Most commonly, they used locally developed structured proformas $(n=13$, $40.6 \%)$. Staff at $12(37.5 \%)$ emergency departments used published scales (table 2); $8(66.6 \%)$ of these were used in conjunction with locally developed proformas or other generic assessments. The SAD PERSONS scale ${ }^{28}$ was the most frequently used scale, being employed in 9 $(28.1 \%)$ of the emergency departments. Two (6.2\%) hospitals used solely the SAD PERSONS scale and clinical judgment of medical staff to assess risk and staff at 1 $(3.1 \%)$ hospital reported using only clinical judgment to assess risk (table 2).

\section{Risk and needs assessment by mental health staff}

Overall, 31/32 (96.9\%) mental health services reported that they carried out risk assessments following selfharm, and 29/32 (90.6\%) reported evaluating service user's needs as part of their wider assessment process. Written guidelines were available to assist clinicians in their psychosocial assessment in 27/32 (87.5\%) services.

\section{Risk tools used by mental health services staff}

A wide range of risk assessment tools were used by clinicians in mental health services. Clinicians most frequently reported using locally developed proformas for

Table 2 Risk assessment tools used by emergency department and mental health staff (categories not mutually exclusive)

\begin{tabular}{|c|c|c|}
\hline Description & $\begin{array}{l}\text { Frequency of use by } \\
\text { emergency departments }\end{array}$ & $\begin{array}{l}\text { Frequency of use by } \\
\text { mental health services }\end{array}$ \\
\hline \multicolumn{3}{|l|}{ Published risk scales* } \\
\hline SAD PERSONS Scale ${ }^{27}$ & 9 & 2 \\
\hline Suicide Intent Scale $e^{29} \dagger$ & 1 & 1 \\
\hline Pierce Suicide Intent Scale $e^{28}$ & 1 & 1 \\
\hline Beck Depression Inventory ${ }^{36}$ & 1 & \\
\hline \multicolumn{3}{|l|}{ All other risk assessment tools } \\
\hline Structured pro forma (developed locally) & 13 & 22 \\
\hline Galatean Risk Screening Tool (GRiST) & 1 & \\
\hline Emergency department mental health/suicide risk assessment form & 3 & \\
\hline Safe-risk pro forma & 1 & \\
\hline Functional analysis of care environments (FACE) & 1 & \\
\hline Emergency department doctors' handbook & 1 & \\
\hline Mental health clustering tool & 1 & \\
\hline Threshold assessment grid (TAG) & 2 & \\
\hline Policy on intranet & 1 & \\
\hline $\begin{array}{l}\text { Risk assessment based on the care programme approach } \\
\text { (or using CPA forms) }\end{array}$ & 3 & 6 \\
\hline CARSO: clinical assessment of risks to self and others & 1 & 1 \\
\hline Rapid assessment and treatment tool & 1 & \\
\hline St George's tool & 2 & \\
\hline Computerised assessment system & 1 & 2 \\
\hline Initial screening assessment form $\ddagger$ & 1 & 1 \\
\hline Risk assessment matrix & 2 & 1 \\
\hline
\end{tabular}


risk assessment ( $\mathrm{n}=22,68.8 \%)$. Three (9.4\%) mental health services used published scales in their assessment of self-harm. One mental health service used the Pierce Suicide Intent Scale $^{29}$ in conjunction with a locally developed proforma $(3.1 \%)$. Two $(6.3 \%)$ mental health services used the SAD PERSONS scale; one of these used the scale in conjunction with the Suicide Intent Scale $^{30}$ and a locally developed pro forma (table 2).

\section{Service quality score}

Fourteen of the $32(43.8 \%)$ hospitals used published scales as part of risk assessment in the emergency department or mental health setting. Overall, service quality scores ranged from 10.5 to 19 , with a median score of 14.5 (IQR 12, 16). Hospitals which used scales had the same median service quality score as those hospitals which did not use scales (median score (IQR): $14.5(12.8,16.4)$ vs $14.5(11.4,16.0), \mathrm{U}=121.0, \mathrm{p}=0.90)$.

\section{Repeat self-harm at 6 months}

Hospitals which used published scales as a component of their risk assessments had a lower median rate of repeat self-harm at 6 months than hospitals which did not (median repeat rate (IQR): $18.5 \%(16.3,20.8 \%)$ vs $22.7 \%$ (20.4, 25.2\%), U=57.0, $\mathrm{p}=0.008)$. When we analysed the repetition data using negative binomial regression, the unadjusted incidence rate ratio was 1.18 (95\% CI (1.00 to 1.37), $\mathrm{p}=0.039$ ), indicating that services which did not use risk scales had rates of self-harm repetition that were almost $20 \%$ higher than services which used such scales.

However, when we adjusted for differences in casemix (by considering potential confounders such as the proportion of patients: with a history of self-harm; who used cutting as a method; who were in current treatment; who were women or aged under 35 years) the association between use of a risk scale and repetition was attenuated (IRR=1.13, 95\% CI (0.984 to 1.29), $\mathrm{p}=0.08)$. Repeat self-harm was explained to a greater extent by casemix factors such as male gender (IRR $=1.3,95 \%$ CI (1.1 to 1.5$), \mathrm{p}=0.001$ for hospitals in the highest vs lowest tertile for proportion of male patients) and history of self-harm (IRR=1.19, 95\% CI (1.0 to 1.4) $\mathrm{p}=0.015$ for hospitals in the highest vs lowest tertile for proportion of patients with a history of previous self-harm).

We conducted a sensitivity analysis to determine whether the effect of risk scales was specific to the emergency setting by using emergency department data only. The rate of repetition was lower for emergency departments that used a published scale (19\% IQR (15.1, $21.1 \%)$ vs $22.3 \%(19.1,25.1 \%)$ ), although statistical evidence for a difference was limited $(\mathrm{U}=70, \mathrm{p}=0.053)$.

\section{DISCUSSION}

\section{Main findings}

In this study of 32 hospitals in England we have shown that a wide variety of tools and scales are used for the assessment of risk following self-harm. There is little consistency in practice. Many services use locally developed proformas or tools of questionable validity for risk assessments. Psychometrically tested scales are in use in about one-third of services, but their use varies between emergency department and mental health settings. Overall, the SAD PERSONS is the most commonly used scale. Our data are descriptive and are primarily based on service level (rather than individual level) outcomes. Therefore, the results should be interpreted cautiously, but our findings suggest that in services where scales are used, the incidence of repeat self-harm may be lower.

\section{Strengths and limitations}

The study was observational in nature and we cannot, of course, infer causation. The analyses are based on aggregate data over a 3-month period in 32 hospitals; therefore, generalisability may be an issue. However, we selected a random national sample of services and it is likely that the findings will be applicable to the rest of England. We believe our results will also be relevant to managed healthcare settings in other countries. Data on service characteristics and use of risk tools were collected through interviews, which may be subject to reporting bias. However, we interviewed the person most closely connected with services, and in all but one centre carried out interviews with emergency department and mental health staff as well as obtaining copies of the risk assessment tools themselves.

We specifically restricted ourselves to scales that had undergone psychometric testing with some assessment of their predictive accuracy for suicidal behaviour or selfharm. Our outcome measures were self-harm repetition at 6 months and self-harm service provision. We did not record community episodes of self-harm. It is possible that had we done so we would not have found the apparent association between use of a scale and self-harm repetition. It is possible that use of the scales may have influenced help-seeking behaviour rather than repetition itself. Neither did we record repeat self-harm which resulted in presentation to hospitals other than those in which the index episodes were identified.

\section{Interpretation and future research}

The wide range of tools in use among emergency department and mental health services suggests that there is little consensus over the best instruments for risk assessment. This probably reflects the poor evidence base and the lack of any 'gold standard' for the assessment of repeat self-harm. Staff at emergency departments employed a particularly wide range of tools, which may reflect the style of service provision in that setting and a 'high risk' approach to management. ${ }^{31} \mathrm{By}$ contrast, mental health staff were less likely to use published risk scales. This could reflect a greater reliance on comprehensive psychosocial assessment.

Perhaps particularly concerning was the fact that locally developed tools were in widespread use in emergency department and mental health settings. This is 
consistent with other reports. ${ }^{13-15} 17$ Locally developed tools are generally not evidence based. They may have unclear scoring criteria and wide variations in structure, content and focus. ${ }^{13}{ }^{14}$ They are used inconsistently across and within hospitals. ${ }^{32-34}$ The Royal College of Psychiatrists recommends that use of locally developed forms should be phased out altogether. ${ }^{34}$

Other services used published scales for risk assessment, but the evidence base for these is also weak. The psychometric properties of some scales have been investigated but their predictive value is very limited. This is perhaps due to the intrinsic properties of the scales themselves but also because of the comparatively low base rate of repeat self-harm (and particularly suicide). On this basis, the National Institute of Health and Care Excellence (NICE) guideline for the longer term management of self-harm recommended that scales should not be used in isolation to predict risks or determine clinical management. ${ }^{9}$ They could be used as an adjunct to assessment. Similarly, recent research has cast doubt on the use of the SAD PERSONS scale (the most commonly used emergency department instrument in our study) because of its consistently poor predictive ability. ${ }^{35} 36$

Interestingly, our study suggested that services which used risk scales may have had lower repetition rates than services which did not. It could be that use of the scales was a marker for more comprehensive services, but this was not borne out by our service quality scores. When we adjusted our models for possible confounders, the apparent protective effect of the use of scales was attenuated. Use of risk scales could also have reflected a more formal approach to assessment across the care pathway.

Alternatively, use of the scales may have influenced patients' willingness to re-present as there is evidence from qualitative work that service users dislike 'tick box' approaches to assessment which may impair therapeutic engagement (as opposed to more holistic assessments which may be experienced as helpful).$^{15}$ In other words, the lower rate of repetition in hospitals using tested scales may be because people have repeat episodes of self-harm in the community (which were unrecorded in this study), and may not return to the hospital service due to finding the assessment an adverse experience. A future study including follow-up of self-harm in the community might help determine the influence of this on subsequent help-seeking behaviour. Further research on the positive and negative impacts of these instruments following self-harm would be of benefit, perhaps using prospective or randomised controlled designs and ideally with a qualitative component seeking perspectives of staff and patients. Until then, it is likely that the indiscriminant use of risk scales in clinical services will continue.

Acknowledgements The authors would like to thank Dr David While for his statistical advice and Dr Matthew Lowe for data collection.

Contributors NK and JC designed the study with input from DG, KH and LD. JC was responsible for data collection. SS and LQ extracted and processed the data. $L Q$ analysed the data with assistance from NK and JC. LQ, JC and NK interpreted the results and wrote the first draft. All the authors contributed to subsequent drafts and have approved the final version of the manuscript.

Funding This paper presents independent research funded by the National Institute of Health Research (NIHR) under its Programme Grants for Applied Research Programme (Grant Reference Numbers RP-PG-0606-1247 and RP-PG-0610-10026). The views expressed are those of the authors and not necessarily those of the NHS, the National Institute of Health Research or the Department of Health.

Competing interests DG, KG and NK are members of the Department of Health's (England) National Suicide Prevention Advisory Group. NK chaired the NICE guideline development group for the longer term management of self-harm, the NICE Topic Expert Group (which developed the quality standards for self-harm services) and the NICE evidence update for self-harm. KH and DG are NIHR senior investigators. KH is also supported by the Oxford Health NHS Foundation Trust and NK by the Manchester Mental Health and Social Care Trust.

Ethics approval The study received ethical approval from Tameside and Glossop NHS Research Ethics Committee in August 2009.

Provenance and peer review Not commissioned; externally peer reviewed.

Data sharing statement No additional data are available.

Open Access This is an Open Access article distributed in accordance with the Creative Commons Attribution Non Commercial (CC BY-NC 3.0) license, which permits others to distribute, remix, adapt, build upon this work noncommercially, and license their derivative works on different terms, provided the original work is properly cited and the use is non-commercial. See: http:// creativecommons.org/licenses/by-nc/3.0/

\section{REFERENCES}

1. Hawton K, Bergen H, Casey D, et al. Self-harm in England: a tale of three cities. Soc Psychiatry Psychiatr Epidemiol 2007;42:513-21.

2. Owens D, Horrocks J, House A. Fatal and non-fatal repetition of self-harm. Systematic review. Br J Psychiatry 2002;181:193-9.

3. Bergen $\mathrm{H}$, Hawton $\mathrm{K}$, Waters $\mathrm{K}$, et al. Premature death after self-harm: a multicenter cohort study. Lancet 2012;380:1568-74.

4. Department of Health. Preventing suicide in England. A cross-government outcomes strategy to save lives. UK: Department of Health, 2012.

5. Kapur N, Steeg S, Webb R, et al. Does clinical management improve outcomes following self-harm? Results from the multicentre study of self-harm in England. PLOS ONE 2013;8:e70434.

6. National Collaborating Centre for Mental Health. Self-harm. The short-term physical and psychological management and secondary prevention of self-harm in primary and secondary care. National Clinical Guideline Number 16. National Collaborating Centre for Mental Health. London: The British Psychological Society and The Royal College of Psychiatrists, 2004.

7. Kapur N, Murphy E, Cooper J, et al. Psychosocial assessment following self-harm: results from the multi-centre monitoring of self-harm project. J Affect Disord 2008;3:285-93.

8. Hawton K. Psychiatric assessment and management of deliberate self-poisoning patients. Medicine 2012;40:71-3.

9. National Collaborating Centre for Mental Health. Self-harm. The NICE guideline on longer-term management. National Clinical Guideline Number 133. National Collaborating Centre for Mental Health. London: The British Psychological Society and The Royal College of Psychiatrists, 2011.

10. Hunter C, Chantler K, Kapur N, et al. Service user perspectives on psychosocial assessment following self-harm and its impact on further help-seeking: a qualitative study. J Affect Disord 2013;145:315-23.

11. Redley M. The clinical assessment of patients admitted to hospital following an episode of self-harm: a qualitative study. Sociol Health IIIn 32:470-85.

12. Bergen $\mathrm{H}$, Hawton $\mathrm{K}$, Waters $\mathrm{K}$, et al. Psychosocial assessment and repetition of self-harm: the significance of single and multiple repeat episode analyses. J Affect Disord 2010;127:257-65.

13. Hawley JC, Littlechild B, Sivakumaran T, et al. Structure and content of risk assessment proformas in mental healthcare. J Mental Health 2006;15:437-48.

14. Higgins $\mathrm{N}$, Watts $\mathrm{D}$, Bindman J, et al. Assessing violence risk in general adult psychiatry. Psychiatr Bull 2005;29:131-3. 
15. Royal College of Psychiatrists. Self-harm, suicide, and risk: helping people who self-harm. Final report of a working group. Royal College of Psychiatrists. London. Royal College of Psychiatrists, 2010.

16. Bossuyt MP, Reitsma BJ, Bruns ED, et al. The STARD statement for reporting studies of diagnostic accuracy: explanation and elaboration. Clin Chem 2003;49:7-18.

17. Singh Pull J. A survey of assessment tools for detecting and managing risk. Ment Health Pract 2011;15:31-3.

18. Libetta C, Burke D, Brennan P, et al. Validation of the Ottawa ankle rules in children. Emerg Med J 1999;16:342-4.

19. Stiell IG, Wells GA, Vandemheen K, et al. The Canadian CT Head Rule for patients with minor head injury. Lancet 2001;357:1391-6.

20. Cooper J, Steeg S, Bennewith O, et al. Are hospital services for self-harm getting better? An observational study examining management, service provision and temporal trends in England. BMJ Open 2013;3:e003444.

21. Gunnell D, Bennewith O, Peters TJ, et al. The epidemiology and management of self-harm amongst adults in England. $J$ Public Health 2005;27:67-73.

22. Bennewith O, Gunnell D, Peters TJ. et al. Variations in the hospital management of self-harm in adults in England: observational study. BMJ 2004;328:1108-9.

23. Cooper J, Kapur K, Dunning J, et al. A clinical tool for assessing risk after self-harm. Ann Emerg Med 2006;48:459-66.

24. Steeg S, Kapur N, Applegate E, et al. The development of a population-level clinical screening tool for self-harm repetition and suicide: the ReACT Self-Harm Rule. Psychol Med 2012;42:2383-94

25. IBM Corp. IBM SPSS statistics for Windows, version 20.0. Armonk, NY: IBM, 2011.

26. Statacorp. Stata statistical software: release 12. College Station Stata Corporation, 2011.
27. Mackway-Jones K. Emergency triage. London: BMJ Publishing Group, 1997.

28. Patterson WM, Dohn HH, Bird J, et al. Evaluation of suicidal patients: the SAD PERSONS scale. Psychosomatics 1983;24:343-9, 348-9.

29. Pierce DW. Suicidal intent in self-injury. Br J Psychiatry 1977;130:377-85.

30. Beck AT, Kovacs M, Weissman A. Assessment of suicidal intention: the scale for suicide ideation. J Consult Clin Psychol 1979;47:343-52.

31. Kapur N, House A, Creed F, et al. General hospital services for deliberate self-poisoning: an expensive road to nowhere? Postgrad Med J 1999;75:599-602.

32. Gale MT, Hawley JC, Sivakumaran T. Do mental health professionals really understand probability? Implications for risk assessment and evidence-based practice. J Ment Health 2003;12:411-24.

33. Hawley JC, Gale MT, Sivakumaran T, et al. Risk assessment in mental health: staff attitudes and an estimate of time cost. J Ment Health 2010;19:88-98.

34. Royal College of Psychiatrists. Rethinking risk to others in mental health services. Final report of a scoping group. London: Royal College of Psychiatrists, 2008.

35. Bolton JM, Spiwak R, Sareen J. Predicting suicide attempts with the SAD PERSONS scale: a longitudinal analysis. J Clin Psychiatry 2012;73:735-41.

36. Saunders K, Brand F, Lascelles K, et al. The sad truth about the SAD PERSONS scale. An evaluation of its clinical utility in self-harm patients. Emerg Med J Published Online First: 29 July 2013. doi:10.1136/emermed-2013-207181

37. Morgan S. Working with risk: practitioner's manual. Brighton: Pavilion Publishing, 2007. 